\title{
ECOPHYSIOLOGY OF BRYOPHYTES IN A CHANGING ENVIRONMENT
}

\author{
Marianna Marschall* \\ Eszterházy Károly University, Institute of Biology, \\ Department of Botany and Plant Physiology, 3300 Eger, Leányka str. 6.; \\ *E-mail: marschall.marianna@uni-eszterhazy.hu
}

\begin{abstract}
Studies of the impact of climate change on plants are generally based on vascular plants. Bryophytes basically differ from tracheophytes in having a smaller size and a poikilohydric strategy for water and nutrients. Their survival and growth are highly dependent on their external environment. Bryophytes are able to lose most of their cell water without dying, and resume normal metabolism after rehydration, gaining positive carbon balance over wet-dry cycles. This sort of adaptation is called desiccation tolerance. Desiccation tolerance is a common phenomenon among bryophytes: cells of bryophytes in exposed sunny sites can switch from full turgor to air dryness quickly, while the species of moist habitats dry more slowly, and can suffer stress by even moderate drying. Bryophytes can maintain efficient photosynthesis under low light conditions, have low chl a/b ratios, and their optimum growth is possible within a limited temperature range. When certain bryophytes' $\mathrm{CO}_{2}$ assimilation is suppressed, photorespiration activity increases and becomes the main electron sink. Bryophytes, as sensitive components of various vegetation types, are capable of effective light absorption during their desiccation, rehydration, freezing and melting, with the help of coexisting alga and vascular plant energy dissipation mechanisms. They have a relatively low optimal temperature for growth (with narrow $T$ range for net photosynthetic gain), with only minor differences between the optimum temperatures for net photosynthesis in polar, temperate and tropical populations of the same species. Bryophytes have a low acclimatization potential for high temperatures, taking into account that they are generally drought avoiders. Temperature acclimatization potential is of high importance for the physiological basis of altitudinal distribution and the likely responses of bryophytes to climate change. Bryophytes with their small and resistant spores are able to disperse over long distances by wind, which might help their survival in a changing environment. Dominant vascular vegetation might change as temperature will increase; however, suitable microhabitats for bryophytes might still persist. The abundance and species composition of bryophytes in plant communities is predicted to be altered, just as the function of the whole ecosystem. Based on recent literature and own data, the author makes an attempt to summarize the physiological mechanisms, morphological features and alternative strategies that make bryophytes successful in a constantly changing terrestrial environment. These plants represent a sophisticated solution to the challenges of life at their
\end{abstract}


scale. Further exploration of bryophyte ecophysiology in the changing and stressful environment will provide new information that will assist bryophyte conservation.

Keywords: bryophytes, ecophysiology, changing environment, desiccation tolerance, photosynthetic adaptation

\section{INTRODUCTION}

The changing environment means the same altering environmental factors for bryophytes as for vascular plants. During global climate change drought, extreme values in the distribution of rainfall or other types of precipitation, more frequent high temperatures, rising $\mathrm{CO}_{2}$ levels, and UV-A, UV-B radiation rise often or continuously occur and can cause abiotic stress. As a result of all of these changes, habitats and microhabitats may change, the desertification of certain areas can start, a change of ecosystem structure and function appears, and the mineral cycle and the local and global carbon balance also change.

Based on recent literature and own data, the author aims to summarize the physiological mechanisms, responses, morphological and other adaptations, and alternative strategies that make bryophytes successful in a constantly changing terrestrial environment.

\section{Responses to water stress}

Bryophytes are ancient land plants. Their desiccation tolerance is general, but not universal. Due to their smaller size and poikilohydric strategy they cannot be independent of the water content of their environment. Their cellular responses to water stress do not differ from those of vascular plants. Therefore bryophytes are ideal model plants to study the physiological basis of desiccation tolerance. The physiology of bryophytes differs in major respects from that of vascular plants by virtue of their smaller size. Unlike vascular plants, the leafy shoots of bryophytes equilibrate rapidly with the water potential in their surroundings and tend to be either fully hydrated or desiccated and metabolically inactive (Proctor et al. 2007b). In the course of drying out and rehydrating they must pass through the levels of water stress 
experienced by drought-tolerant vascular plants. They only transiently face the problem of metabolizing under water stress. It is similar to a "drought avoidance" strategy in vascular plants (Marschall 2010). The time required to recover from desiccation increases and degree of recovery decreases with length of desiccation; both also depend on temperature and intensity of desiccation. Recovery of respiration, photosynthesis and protein synthesis takes place within minutes or an hour or two; recovery of the cell cycle, food transport and the cytoskeleton may take 20 hours or more. Positive carbon balance is essential to surviving repeated cycles of drying and wetting; significant growth requires continuously wet periods of a few days or more. The mechanisms of desiccation-tolerance in bryophytes, including expression of LEA proteins, high content of non-reducing sugars (Marschall et al. 1998) and effective antioxidant and photo-protection, are at least partly constitutive, allowing survival of rapid drying, and employ an active rehydration-induced repair and recovery mechanism. During their recovery phase the changes in gene expression resulting from mRNA sequestration and alterations in translational controls elicited upon rehydration are also important to repair processes following rewetting (Proctor et al. 2007b). Desiccationtolerant angiosperms do not survive if they are dehydrated in less than 12 hours, because of the existence of time-consuming inductive cell protection mechanisms (Oliver et al. 2000, Marschall 2010). However, desiccation-tolerant bryophytes can survive desiccation even if it occurs in less than 12 hours, due to their constitutive protection and an active rehydration-induced repair and regeneration mechanism. To understand the differing physiological processes and stress responses of bryophytes compared with higher plants' reactions it is essential to know the actual water status of the bryophyte tissue. Cell water relations in bryophytes essentially are the same as those of other plant cells and can be described by the 'Höfler diagram'. Bryophytes' pressure (P-V) curves and Höfler diagrams are different from those typical for vascular plants in only a single but essential respect: substantial external capillary water is generally present, and is physiologically important (Proctor 2000). Surface water amount can vary widely without affecting cell water status, which can result in difficulties in expressing precise actual water content (WC). Knowledge of fullturgor WC is principal to calculate RWC and can be determined 
only from experimental P-V measurements. The different adaptive types of bryophytes and higher plant cells respond similarly to water deficit. Bryophytes are much more tolerant of high (or very low) temperatures dry than wet. Species of constant moist and shade are the most sensitive to desiccation.

\section{Adaptation in the photosynthesis of bryophytes, light protection mechanisms}

Differing and also frequently changing habitat light conditions, several types of bryophyte morphology for the operation of $\mathrm{CO}_{2}$ diffusion, different degrees of desiccation-tolerance in the different bryophyte species, as various factors, necessitate the existence of different forms of photosynthesis adaptation. Bryophyte species, although living in a wide range of light conditions, still show uniform features as shade plants (based on evidence including fine structural features of the chloroplasts, the typically low chl a/b ratios in the range of shade-adapted vascular plants, and the saturation of their photosynthesis at $20 \%$ of full sunlight), therefore tradition has regarded them as shade plants (Marschall and Proctor 2004). Bryophytes include but are not inherently shade plants. It is intuitively reasonable that poikilohydric photosynthetic organisms should be adapted to function at relatively low light levels. During periods of bright, dry sunny weather bryophytes will be dry and metabolically inactive. Most of their photosynthesis takes place in rainy or cloudy weather $(<20 \%$ of full sunlight). Best adapted to photosynthesis under high light are presumably the species of mires, springs and other wet habitats, which remain constantly moist in full sun. There is great variation in the light responses of bryophytes: shade-loving species saturate at a PPFD of 100-300 $\mu \mathrm{mol} \mathrm{m} \mathrm{m}^{-2} \mathrm{~s}^{-1}$ (responses are similar to those of shade-loving vascular plants), sun-exposed species at a PPFD of $1000 \mu \mathrm{mol} \mathrm{m} \mathrm{m}^{-2} \mathrm{~s}^{-1}$. In this species REFR rises almost linearly (does not saturate) with increasing irradiance, and they show extraordinary high levels of NPQ, which can be suppressed by DTT. This suggests high levels of xanthophyll-cycle-mediated photoprotection, similar to that of higher plants, extra excitation energy dissipating as heat. 1-qP generally stabilises at around 0.3 to 0.4 . Responses of this kind are found in a taxonomically and ecologically diverse range of bryophytes. PPFD response patterns 
in bryophytes having complex ventilated photosynthetic systems are similar to those of vascular plants and very different from sunexposed responses (Marschall et al. 2000). Photosynthetic responses of a range of Polytrichaceae vary in lamella development (Proctor et al. 2007a). In sun-exposed bryophytes $\mathrm{O}_{2}$ and $\mathrm{CO}_{2}$ are largely interchangeable as electron sinks and $\mathrm{CO}_{2}$-uptake accounts for $\sim 60 \%$ of the low PPFD saturation value. Shade-adapted species appear less able to use $\mathrm{O}_{2}$ as electron sink, or to generate high NPQ at high irradiance. Light-saturation levels for species of open sunexposed habitats are lower than for vascular sun plants and are probably limited by $\mathrm{CO}_{2}$ diffusion into unistratose leaves; this limit can only be exceeded by bryophytes with ventilated photosynthetic tissues, which provide an increased area for $\mathrm{CO}_{2}$ uptake (Marschall et al. 2000). Contrary to bryophyte species of wet and constantly moist areas, species of open sun-exposed habitats can reach air-dry state from full turgor relatively quickly.

The retaining of photosynthetic capacity in bryophytes after 7d-darkness (photosynthetic activity immediately recovered after the subsequent illumination) is in contrast with the loss of photosynthetic capacity and degreening in higher plants exposed to prolonged dark. These responses of photosynthesis (and also of respiration) presumably contribute to conservation of resources when photosynthesis is prevented (by, for example, temporary burial under dead leaves) but allows rapid resumption of photosynthesis when the plant is illuminated (Marschall 2010).

The simultaneous presence of excitation energy and molecular oxygen, as occurs in the membranes of plants, may lead to the formation of reactive oxygen species and thus to photoinduced damage (Croce 2015). In desiccation-tolerant and open sunexposed habitat bryophytes thermal energy dissipation with extremely high NPQ values is the most important element of water stress and high-light protection mechanisms. The safest and most flexible way of dissipating extra excitation energy absorbed by chlorophylls is the release of heat in the photosynthetic apparatus. $\mathrm{NPQ}$, also known as non-photochemical quenching, consists of heat dissipation of chlorophyll $\left(1 \mathrm{Chl}{ }^{*}\right)$ in excited singlet states. Kinetically, NPQ is a complex process, its biochemical, biophysical, physiological and ecological characterization has intensified over the last 20 years. Basically, 3 components are involved in NPQ regulation: (1) the proton gradient $(\Delta \mathrm{pH})$ generated between the 
thylakoid membrane lumen and the side of the stroma generated by the photosynthetic proton pump; (2) violaxanthin cycle activity and the formation of zeaxanthin; (3) the PsbS protein (GarcíaPlazaola et al. 2012). Although many of the light protection mechanisms of bryophytes are common with higher plants, there are also fundamental differences. In other respects, the mechanisms found in the algae ancestors that vascular plants have lost during their evolution have been retained by bryophytes (eg. LHCSR protein related thermal energy dissipation). Many bryophyte species during their desiccation, rehydration, freezing and melting are capable of absorbing light, without suffering photooxidative damage, due to their effective light protection mechanisms of energy dissipation. In vascular plants, NPQ (nonphotochemical quenching) is based on the activity of PSBS protein, while in Chlamydomonas reinhardtii green algae it requires LHCSR, another protein (LHC-like polypeptide). For the time being, Physcomitrella patens is the only known / described bryophyte in which both of these proteins are present and active in the induction of NPQ. Marschall and co-workers' (2017) investigations on desiccation-tolerant Porella platyphylla (Marschall and Proctor 1999) and desiccation-sensitive Sphagnum angustifolium were directed at detecting photosynthetic activity, light protection and other regeneration mechanisms during varying degrees and durations of desiccation and rehydration with the use of violaxanthin cycle inhibitor, plastis and nuclear-encoded protein synthesis inhibitors. They showed that during the regeneration of thylakoid function related photosynthetic processes in the light xanthophyll cycle has great importance: higher zeaxanthindependent and lower ratio of DTT-insensitive NPQs were confirmed. Desiccation-tolerant bryophytes are characterized by the fact that they do not suffer from photooxidative damage due to the coexistence of both algal and higher plants zeaxanthindependent NPQ mechanisms and also a desiccation-induced thermal energy dissipation.

\section{Alternative e-sinks: FLV-, photorespiration-dependent e-sinks}

At least two large electron sinks, FLV-dependent and photorespiration-dependent electron sinks, were found to operate in photosynthetic organisms. Both electron sinks guide excess photon-energy to $\mathrm{O}_{2}$ (Ilik et al. 2017). Photosynthetic organisms in 
aquatic environments prefer the FLV-dependent electron sink before photorespiration, while higher plants use photorespiration as an electron sink (Shimakawa et al. 2017a). Using land plants (liverworts, ferns, gymnosperms, and angiosperms), Hanawaa and co-workers (2017) compared photorespiration activities and estimated the electron flux driven by photorespiration to evaluate its electron-sink capacity at $\mathrm{CO}_{2}$-compensation point. Liverworts showed photorespiration activity in which electron flux occupied more than $70 \%$ of the photosynthetic linear electron flux under conditions when $\mathrm{CO}_{2}$ assimilation was suppressed. Starting from liverworts to gymnosperms, photorespiration activity increased and became the main alternative electron flux. Their results show that the first land plants, liverworts, started to use photorespiration as an electron sink. When certain bryophytes' $\mathrm{CO}_{2}$ assimilation is suppressed, photorespiration activity increases and becomes the main electron sink (Hanawaa et al. 2017). Gerotto and co-workers (2017) showed that in Physcomitrella patens, Flavodiiron (FLV) proteins act as an electron sink to avoid photosynthetic electron transport chain over-reduction after any increase in illumination and are fundamental for protection under fluctuating light conditions.

\section{Physiological adaptations, responses to temperature in bryophytes}

Bryophytes have a relatively low optimal temperature for growth (with narrow $\mathrm{T}$ range for net photosynthetic gain), including only minor differences between the optimum temperatures for net photosynthesis in polar, temperate and tropical populations of the same species. Bryophytes have a low acclimatization potential for high temperatures, taking into account that they are generally drought avoiders (He et al. 2016). Temperature acclimatization potential is of high importance for the physiological basis of altitudinal distribution and the likely responses of bryophytes to climate change. The dominant vascular vegetation presumably changes as T rises; however, a microhabitat suitable for bryophytes can be further preserved. For example, the appearance and occurrence of desert mosses in certain microclimatic areas of desert habitats is unique and a real milestone. 


\section{Other bryophyte ecophysiology related thoughts}

In a globally changing environment certain bryophyte species can become extinct, contributing to a decline in biodiversity, and invasive species may spread, displacing their less competitive taxonomic relatives. It is important to acquire knowledge about the reproductive and ecophysiological properties of invasive bryophytes and also to further develop in vitro bryophyte culture techniques and to take further steps to utilize them for conservation biological purposes. Bryophytes with their small and resistant spores are able to disperse over long distances by wind and other carriers, which might help their survival in a changing environment. The effects of UV-A, B radiation on bryophytes have usually been studied in laboratory experiments. Less data is available from natural habitats. Growth responses to seasonal changes in UV radiation have been observed, mainly in circumpolar heights.

\section{CONCLUSION}

Bryophytes share most of their physiology with other land plants (Proctor 2000). Modern bryophytes are the end-product of the same $400+$ million year period of separate evolution as modern vascular plants. They are not primitive precursors of vascular plants, but diverse and highly evolved representatives of an alternative adaptation strategy. Due to their successful strategy they are prominent in oceanic temperate forests, tropical cloud forests, bogs and fens, polar and alpine fellfields and tundras. The dominant vascular vegetation presumably changes as $\mathrm{T}$ rises; however, a microhabitat suitable for bryophytes can be further preserved. Further exploration of bryophyte ecophysiology in a changing and stressful environment will provide new information that will assist bryophyte conservation.

Acknowledgement - The author is grateful to Albert Vermes for reading and correcting the English of the manuscript and also for the financial support of the grant EFOP-3.6.1-16-2016-00001 ("Complex improvement of research capacities and services at Eszterházy Károly University"). 


\section{REFERENCES}

Croce, R. (2015). PsbS is the plants' pick for sun protection. Nature Structural \& Molecular Biology, 22(9): 650-652.

García-Plazaola, J.I., Esteban, R., Fernández-Marín, B., Kranner I. \& Porcar-Castell, A. (2012). Thermal energy dissipation and xanthophyll cycles beyond the Arabidopsis model. Photosynthesis Research 113: 89-103.

Gerotto, C., Alboresia, A., Meneghessoa, A., Jokelb, M., Suorsab, M., Aro, E. \& MorosinotTo, T. (2016). Flavodiiron proteins act as safety valve for electrons in Physcomitrella patens. PNAS 113: 12322-12327.

HanaWaA, H., Ishizakib, K., NohiraA, K., Takagia, D., ShimakawaA, G., SejimaA, T., ShakUA, K., MaKinoc, A. \& MiYAKEA C. (2017). Land plants drive photorespiration as higher electron-sink: Comparative study of post-illumination transient $\mathrm{O}_{2}$ uptake rates from liverworts to angiosperms through ferns and gymnosperms. Physiologia Plantarum 161: 138-149.

HE, X., HE, K.S. \& HYvöNEN, J. (2016). Will bryophytes survive in a warming world? Perspectives in Plant Ecology, Evolution and Systematics 19: 49-60.

Ilik, P., Andrej Pavlovic, A., Kouril, R., Alboresi, A., Morosinotto, T., Allahverdiyeva, Y., ARo, E., YAmamoto, H. \& Shikanai, T. (2017). Alternative electron transport mediated by flavodiiron proteins is operational in organisms from cyanobacteria up to gymnosperms. New Phytologist Rapid Report doi: 10.1111/nph.14536, pp. 1-6.

Marschall, M., Borbély, P. \& Sütő, Sz. (2017). Újranedvesedés alatti fényvédelmi és regenerációs mechanizmusok háttérfolyamatainak, komponenseinek vizsgálata kiszáradástürō és kiszáradásérzékeny mohafajokban. (Background processes and the components of photoprotection and regeneration under rehydration in desiccation tolerant and desiccation sensitive bryophytes). In: GYÖRGYEY, J. (ed.) A Magyar Növénybiológiai Társaság XII. Kongresszusa, Magyar Növénybiológiai Társaság, 15 p.

MaRsChall, M. (2010). Photosynthetic responses, carbohydrate composition and invertase activity in fructan accumulating bryophytes (Porella platyphylla and Sphagnum flexuosum) under different environmental conditions (carbohydrate treatments, dark starvation, low temperature, desiccation). Acta Biologica Hungarica 61: 120-129.

Marschall, M., Proctor, M.C.F. \& Smirnoff, N. (1998). Carbohydrate composition and invertase activity of the leafy liverwort Porella platyphylla. New Phytologist 138: 343-353.

Marschall, M., Proctor, M.C.F \& Smirnoff, N. (2000). Aspects of the photosynthetic responses of bryophytes. Journal of Experimental Botany 51: 58.

Marschall, M. \& Proctor, M.C.F. (1999). Desiccation tolerance and recovery of the leafy liverwort Porella platyphylla (L.) Pfeiff.: chlorophyll-fluorescence measurements. Journal of Bryology 21: 257-262.

MARSChAll, M. \& PRoctor M.C.F. (2004). Are bryophytes shade plants? Photosynthetic light responses and proportions of chlorophyll a, chlorophyll b and total carotenoids. Annals of Botany 94: 593-603.

Oliver M.J., TubA, Z. \& Mishler B.D. (2000). The evolution of vegetative desiccation tolerance in land plants. Plant Ecology 151: 85-100. 
Proctor, M.C.F. (2000). Physiological Ecology. In: Shaw, J. \& Goffinet, B. (eds.): Bryophyte Biology. Cambridge, Cambridge University Press, pp. 225-247.

Proctor, M.C.F., Ligrone, L. \& DucketT, J.G. (2007a). Desiccation tolerance in the moss Polytrichum formosum: physiological and fine-structural changes during desiccation and recovery. Annals of Botany 99: 75-93.

Proctor, M.C.F., Oliver, M.J., Wood, A.J., AlPert, P., Stark, L.R., CleavitT, N.L. \& MishleR, B.D. (2007b). Desiccation-tolerance in bryophytes: a review. The Bryologist 110(4): 595-621.

Shimakawa, G., Ishizaki, K., Tsukamoto, S., Tanaka, M., Sejima, T. \& Miyake, C. (2017). The Liverwort, Marchantia, Drives Alternative Electron Flow Using a Flavodiiron Protein to Protect PSI. Plant Physiology 173: 1636-1647.

(submitted: 15.11.2017, accepted: 22.12.2017) 